\title{
Mapping turbidity layers using seismic oceanography methods
}

\author{
E. A. Vsemirnova ${ }^{1, *}$, R. W. Hobbs ${ }^{1}$, and P. Hosegood ${ }^{2}$ \\ ${ }^{1}$ Department of Earth Sciences, Durham University, Durham, DH1 3LE, UK \\ ${ }^{2}$ School of Marine Science and Engineering, Plymouth University, Plymouth PL4 8AA, UK \\ *now at: Geospatial Research Ltd, Durham University, Durham DH1 3LE, UK \\ Correspondence to: R. W. Hobbs (r.w.hobbs@durham.ac.uk)
}

Received: 25 May 2011 - Published in Ocean Sci. Discuss.: 18 August 2011

Revised: 12 December 2011 - Accepted: 22 December 2011 - Published: 10 January 2012

\begin{abstract}
Using a combination of seismic oceanographic and physical oceanographic data acquired across the FaroeShetland Channel we present evidence of a turbidity layer that transports suspended sediment along the western boundary of the Channel. We focus on reflections observed on seismic data close to the sea-bed on the Faroese side of the Channel below $900 \mathrm{~m}$. Forward modelling based on independent physical oceanographic data show that thermohaline structure does not explain these near sea-bed reflections but they are consistent with optical backscatter data, dry matter concentrations from water samples and from seabed sediment traps. Hence we conclude that an impedance contrast in water column caused by turbidity layers is strong enough to be seen in seismic sections and this provides a new way to visualise this type of current and its lateral structure. By inverting the seismic data we estimate a sediment concentration in the turbidity layers, present at the time of the survey, of $45 \pm 25 \mathrm{mg}^{-1}$. We believe this is the first direct observation of a turbidity current using Seismic Oceanography.
\end{abstract}

\section{Introduction}

Turbidity layers are some of the largest sediment-laden underflows that occur in ocean basins. In a geological context, these layers play an important role in transporting fluvial, littoral and shelf sediments into deep ocean environments. They may be sourced from sediment-laden river flow cascading down submarine canyons, slope failure, or by the remobilisation of unconsolidated sediment by strong currents. Turbidity layers are typically defined as relatively dilute flows in which particles are dominantly supported by fluid turbulence with sediment volume concentrations of $<\sim 10 \%$. At higher sediment concentrations grain collision is more frequent and the flow dynamics are changed (Sumner et al., 2009). A large number of experimental studies on turbidity layers are available (e.g. Middleton, 1966; Sumner et al.,
2009), however natural turbidity layers and other sedimentladen transient currents are hard to observe and study, due to their irregular occurrence and often destructive nature (Hay, 1987). Hence our knowledge of the turbidity layers is based largely on indirect observations of the modern seafloor from multibeam bathymetry surveys (Kuijpers et al., 2002), highresolution seismic surveys especially those designed for observations of geohazards (Bulat and Long, 2001; Meiburg and Kneller, 2010) and the study of contourites (Masson et al., 2010; Koenitz et al., 2008); together with direct observation of suspended sediment of the neptheloid layer from optical backscatter or transmissometer and sampling either in Niskin bottles or sediment traps (Bonnin et al., 2002; van Raaphorst et al., 2001; Hosegood and van Haren, 2004).

\section{Turbidity layers in the Faroe-Shetland Channel}

The Faroe-Shetland Channel (FSC) $\left(60^{\circ} \mathrm{N}, 6^{\circ} \mathrm{W}-63^{\circ} \mathrm{N}\right.$, $1^{\circ} \mathrm{W}$ ) is an elongate basin that trends NE-SW between the West Shetland Shelf and the Faroe Shelf (Fig. 1c). It is one of the major conduits of the global thermohaline system as it connects the deep waters of the Norwegian Basin with the Iceland Basin and Atlantic ocean. Turrell et al. (1999) identify five major water masses in the FSC defined by differences in temperature, salinity and provenance. These are North Atlantic Water (NAW), Modified North Atlantic Water (MNAW), Arctic Intermediate/North Icelandic Water (AI/NIW), Norwegian Sea Arctic Intermediate Water (NSAIW) and Faroe Shetland Channel Bottom Water (FSCBW). The classification can be simplified into two groups based on transport direction and water depth, which we will refer to as surface water and bottom water. The surface water (NAW, MNAW and AI/NIW) are essentially warmer, higher salinity water masses and have a transport direction from the south-west to the north-east, with a base in the FSC at approximately $500 \mathrm{~m}$ below sea-level. The bottom 

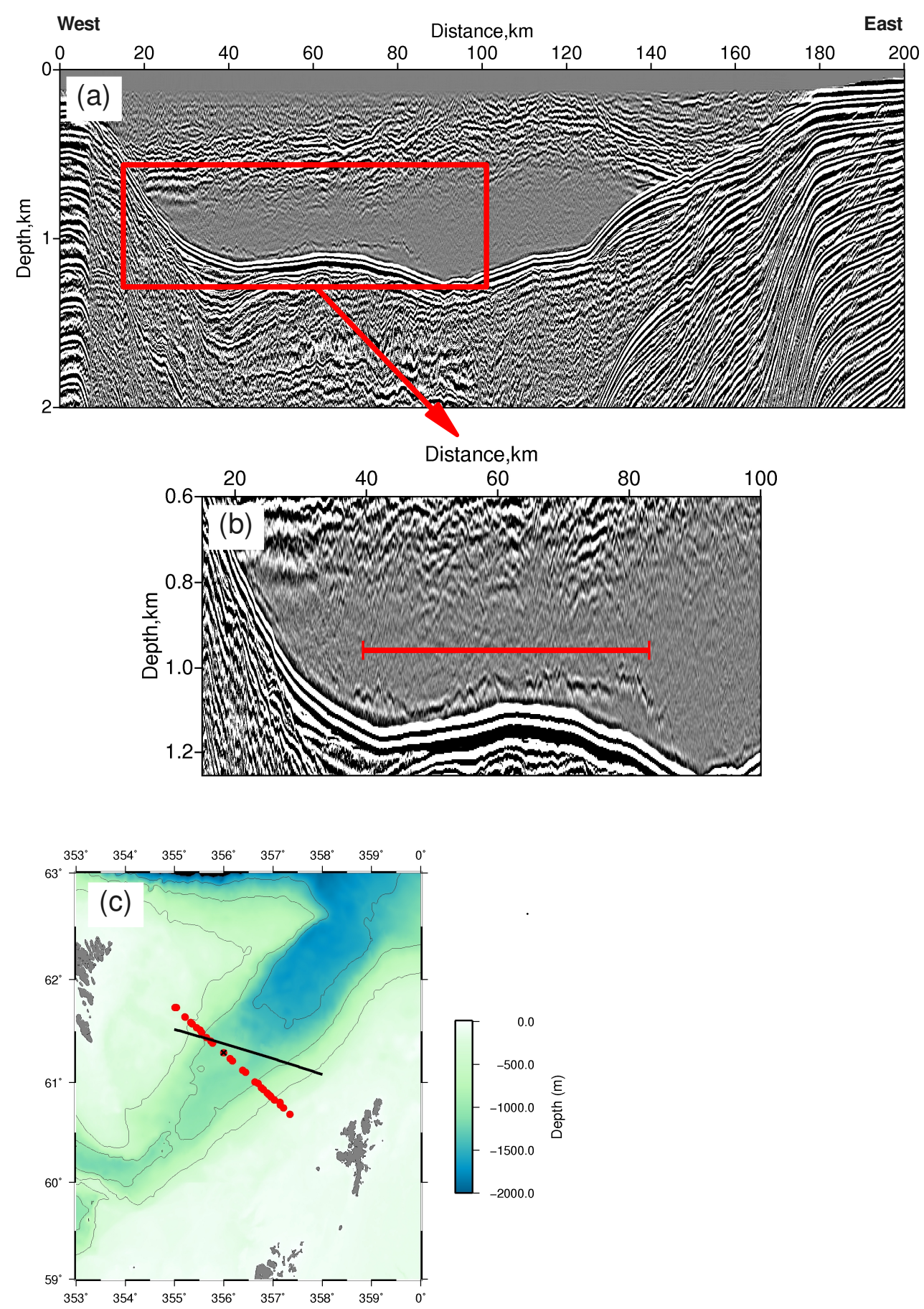

Fig. 1. (a) a depth converted stacked seismic section of the FAST profile (England et al., 2005) reprocessed to recover the reflectivity in the water layer. The seabed reflection is the high amplitude event that can be traced from the centre of the trough at about $1.2 \mathrm{~km}$ depth onto the margins. The band of reflectivity at a depth of about $500 \mathrm{~m}$ is caused by mixing of the North Atlantic Water with the Faroe-Shetland Channel Bottom Water. (b) the inset in rectangle focuses on the near-bed reflections between 65 and $82 \mathrm{~km}$ of the profile which we investigate in this paper. The red line shows the section of data used to compute the histograms in Fig. 4. (c) a map showing the location of profiles used in this study: black line: the FAST seismic profile; red dots: locations of CTD and moorings (Bonnin et al., 2002; Hosegood et al., 2005) cross signifies location used for modelling sound-speed and density profiles (see Fig. 2). 
water (NSAIW and FSCBW) are cold, low salinity, water masses flowing from the north-east to the south-west entirely contained within the FSC. The boundary zone between these two water types is a complex mix of waters and will vary seasonally and over time (Sherwin et al., 2006, 2008).

The shape of the Faroe-Shetland Channel and the orientation of the Wyville-Thomson Ridge effects on the strength of the bottom currents, firstly funnelling these waters together and then deflecting most of the water mass by ninety degrees into the Faroe bank Channel. Hansen and Østerhus (2000) estimate the average flow of bottom water in the FSC to be 3 Sv. Direct measurements at $1000 \mathrm{~m}$ depth on the Shetland side of the FSC show a variable current speed with a mean of $0.25 \mathrm{~m} \mathrm{~s}^{-1}$ with an $\mathrm{M}_{2}$ period with occasional peaks in speed of over $0.5 \mathrm{~m} \mathrm{~s}^{-1}$ (Bonnin et al., 2002). These bottom currents have sufficient strength to mould and rework the seafloor sediments within the FSC (Stoker et al., 1998; Bonnin et al., 2002).

The emergence of 3-D seismic acquisition as a tool for regional reconnaissance for the hydrocarbons industry as well as oil field development has resulted in nearly complete coverage of the FSC area by seismic reflection imaging. Highresolution seismic profiles acquired by the British Geological Survey in the FSC area, were integrated with the 3-D data to produce a regional image of the sea floor with an aim to identify seabed hazards (Bulat and Long, 2001; Masson et al., 2010). These detailed images of the seabed reveal a number of sedimentary processes at work adjacent to and within the FSC. Of particular interest is an extensive network of long mounds that run sub-parallel to the strike of the slope between the $900 \mathrm{~m}$ and $1400 \mathrm{~m}$ isobaths. The network is restricted to the slope area but appears to cover it completely (Bulat and Long, 2001, their Fig. 2). One of the proposed mechanisms for generating these features are sediment waves produced by turbidity-layers creating a series of channels and levees. The irregular character and internal geometry of the mounds are indicative of erratic and turbulent flow.

\section{Data sets}

To date there has not been an integrated physical oceanography and seismic imaging survey with coincident and colocated sampling to examine turbidity layers. So we draw on two surveys, described below, that provide evidence of suspended particulate matter (SPM) that were acquired at different times but in the same region of the Faroe-Shetland channel (Fig. 1). Seismic data (FAST) were obtained during summer 1994, with near ideal weather conditions with wind speeds of less than force 3 (England et al., 2005). Physical oceanography data comes from an array of four moorings (PROCS-Processes at the Continental Slope) which was deployed during spring (April-May) and late summer (September) 1999 (Bonnin et al., 2002). The dynamics that dominate large resuspension events, and a possible mechanism for the formation of turbidity layers is the passage of solibores up the continental slope (Hosegood et al., 2004; Hosegood and van Haren, 2005). Long-term moorings deployed between the two PROCS cruises showed that these events occurred with a 3-5 day periodicity. Other observations of highly nonlinear waves near the sea bed that could also promote resuspension at depth were attributed to the internal tide (Hall et al., 2011). Thus, the hydrodynamics that drive the resuspension events observed in the 1994 FAST data appear to be ubiquitous throughout the FSC, implying that a comparison between the FAST and PROCS data is valid despite the different periods of observation.

\subsection{Seismic reflection}

The seismic line (FAST) which traverses the whole width of the Faroe-Shetland Trough (Fig. 1c) (England et al., 2005) was acquired with the original objective to map the structure of the sedimentary basin and underlying basement. The acquisition used a 1471 ( $8970 \mathrm{cu}$ in) air-gun source optimised for low frequencies (bandwidth $6-60 \mathrm{~Hz}$ ) and a $6 \mathrm{~km}$ 240-channel hydrophone receiver array towed at $18 \mathrm{~m}$ depth. Though the acquisition configuration and the source were designed specifically for deep seismic profiling, the reprocessed section presented here can still produce an image of the overlying water column (Fig. 1a) as demonstrated by Holbrook et al. (2003). The processing sequence for seismic data was modified to include an eigenvector filter to suppress the direct-wave between the seismic source and receiver array which obscures the weak reflectivity from the water column. This reprocessing reveals a band of seismic reflectivity centred around $500 \mathrm{~m}$ which correlates with the boundary between the warmer surface waters and the colder bottom waters (Turrell et al., 1999). In addition, a discontinuous reflection can be traced as a thin layer on the western slope and along the base of the channel. Figure $1 \mathrm{~b}$ shows an expanded section focused on the near sea-bed. The amplitude variations along the reflection are indicative of the complex 3-D nature of this boundary (Hobbs et al., 2006). Below this reflection, for the bandwidth of $6-60 \mathrm{~Hz}$, there is a lack of reflectivity in the interval immediately overlying the seabed.

\subsection{Physical oceanography datasets}

In this study we used data from Optical Back-Scatter (OBS) measurements of suspended sediment, using a Seapoint STM sensor, and water samples taken during Conductivity Temperature Depth (CTD) casts during the PROCS programme in 1999, together with measurements from sediment traps attached to moorings deployed on a transect across the Shetland side of the channel (Bonnin et al., 2002; Hosegood et al., 2005) (Fig. 1c). The CTD data (Fig. 2a, b) shows no significant changes in either temperature or salinity in the proximity of the seabed suggesting the deeper reflections observed on 

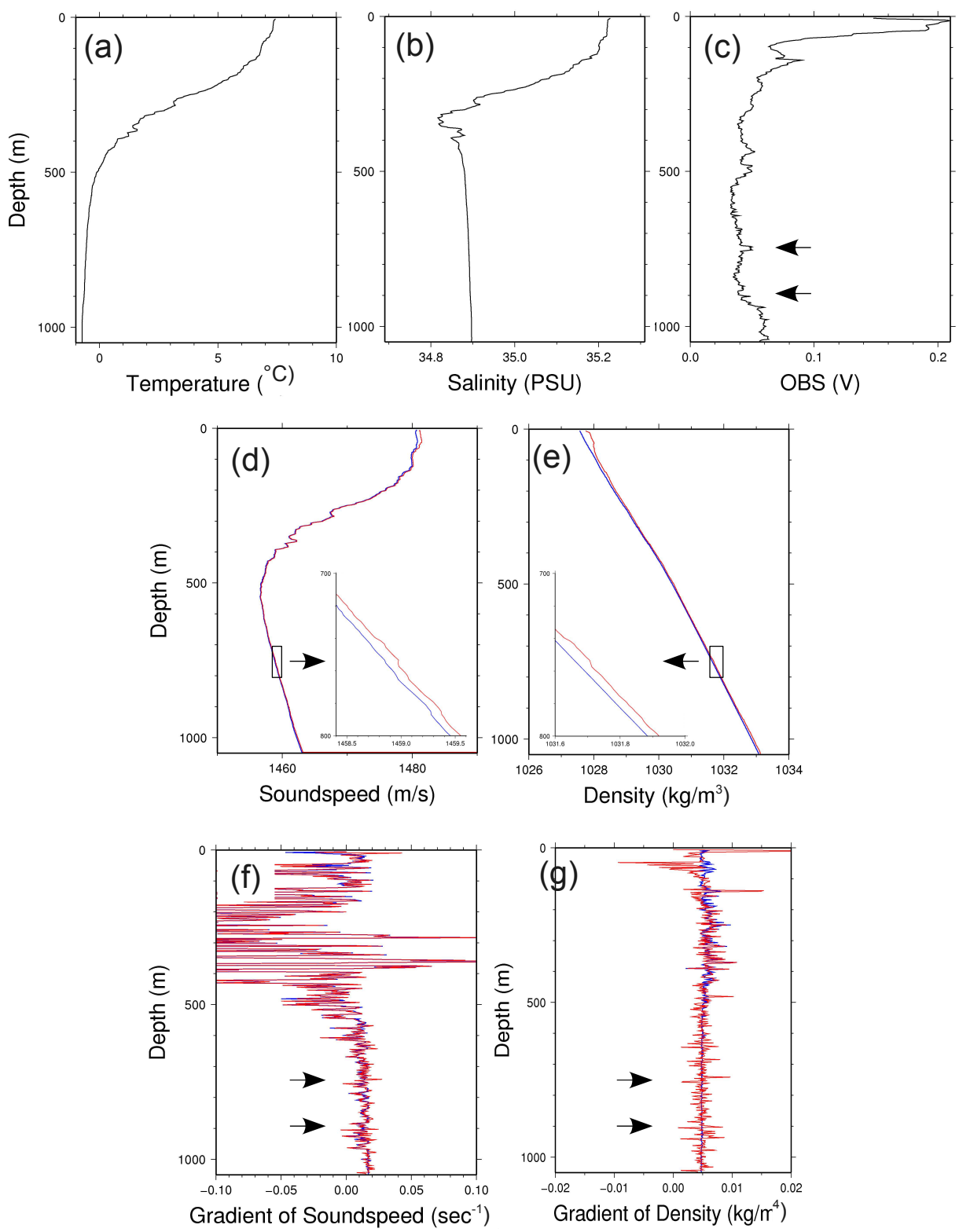

Fig. 2. (a) temperature, (b) salinity and (c) optical back-scatter from the CTD cast (crossed red dot Fig. 1c). (d) corresponding sound-speed and (e) the density profiles without (blue) and with (red) the addition of suspended sediment (assumed to be quartz). The intrusion at $750 \mathrm{~m}$ shown in insert. (f) and (g) the vertical gradient of sound-speed and density respectively again without and with suspended sediment. The effects of intrusion at $750 \mathrm{~m}$ and near seabed sediment load are highlighted by arrows.

the seismic image (Fig. 1b) are wholly within the FSCBW. However, there is evidence of a change in suspended sediment, both dry matter from water samples and high OBS readings close to the sea-bed (Fig. 2c; Bonnin et al., 2002, their Fig. 2). The addition of suspended sediment will change the bulk average sound-speed and density which we propose causes the change in impedance necessary to produce the observed seismic reflection which we can verify through modelling.

\section{Modelling}

To test our hypothesis that measurable reflections can be generated by suspended sediment we perform forward modelling of seismic response based on the temperature, salinity and optical back-scatter measurements from a CTD cast (Fig. 2a, $\mathrm{b}$ and $\mathrm{c}$ ). Initially, we compute the background sound-speed and density profiles using the UNESCO equations of state (Fofonoff and Millard, 1983) assuming no suspended sediment (Fig. 2d, e blue line). From these profiles we can calculate the vertical derivatives (Ruddick et al., 2009) which, 
when combined to form the impedance contrast and convolved with the seismic source wavelet, will produce a seismogram similar to that observed experimentally. The result (Fig. 3 blue line) shows a band of strong reflectivity from 0.3 to $0.6 \mathrm{~s}$ travel-time which equates to depths of 200 to $400 \mathrm{~m}$ that correlates well with the temperature and salinity change between surface and bottom waters.

We repeat the modelling exercise but this time including the effect of the sediment load (Fig. 2c) with the depth dependent density and sound-speed modified using the equation

$\eta_{\text {mod }}(z)=(1-\phi) \eta_{\text {water }}(z)+\phi \eta_{\text {sediment }}(z)$

where $\phi$ is the fraction of sediment by volume and $\eta$ represents either the sound-speed or density. We consider the mixture at any depth as quasi-homogeneous because of the approximate $10^{6}$ scale factor between the size of the sediment particle and the seismic wavelength (Wu and Aki, 1988); this form of averaging is widely used elsewhere (e.g. see for example Lewis et al., 2009). The sediments on the slope are of glacial origin and composed mainly of coarse sands and gravel (Stoker et al., 1993) confirmed by direct sampling which showed that the suspended sediment at depths greater than $700 \mathrm{~m}$ was mainly lithogenic in origin (Bonnin et al., 2002). So we assumed the suspended sediment would be largely composed of quartz with bulk values of $6000 \mathrm{~m} \mathrm{~s}^{-1}$ and $2700 \mathrm{~kg} \mathrm{~m}^{-3}$ for sound-speed and density respectively. The fraction of sediment $(\phi)$ is more difficult to quantify. The OBS signal depends on the particle size and shape (Bunt et al., 1999). Grain size analysis is beyond the scope of this paper and quantitatively we do not use it in our calculations. However, the data on sediment traps from PROCS were published in (van Raaphorst et al., 2001 and references therein). Median grain size was found to decrease with depth over the slope, from $274 \mu \mathrm{m}$ at $649 \mathrm{~m}$ to $158 \mu \mathrm{m}$ at $801 \mathrm{~m}$. A later study (Bonnin et al., 2005) found the median grains size of the surface sediment to be approximately $150 \mu \mathrm{m}$, and to remain at this value at depths greater than $600 \mathrm{~m}$. Approximately $70 \%$ of sediment fell within the size range 63$250 \mu \mathrm{m}$ (Bonnin et al., 2005 their Fig. 7). Benns and Pilgrim (1994) give sensitivities from $1.104 \mathrm{mV}$ per $1 \mathrm{mg}^{-1}$ for fine sediments (particle size of $12.7 \mu \mathrm{m}$ ) to $0.151 \mathrm{mV}$ per $1 \mathrm{mg} \mathrm{l}^{-1}$ for coarse sediments (particle size of $192 \mu \mathrm{m}$ ) and a well defined linear response with correlation coefficients of over 0.99 over a range of concentrations. Similar sensitivities are given by Rogers and Raven (2008). Given the likely grain size range we opt for the calibration based on a poly-disperse distribution ranging from 12.7 to $192 \mu \mathrm{m}$ which gives a sensitivity of $0.438 \mathrm{mV}$ per $1 \mathrm{mg} \mathrm{l}^{-1}$ (Benns and Pilgrim, 1994). Using the observed OBS signal (Fig. 2c) gives a depth varying concentration which has a value of 0.000037 at $1000 \mathrm{~m}$.

The difference to both the sound-speed and density profiles caused by the addition of calculated the suspended sediment are small (Fig. 2d, e). However, the absolute values of density and sound-speed are not important as the seismic reflection is only sensitive to the change over depths that are

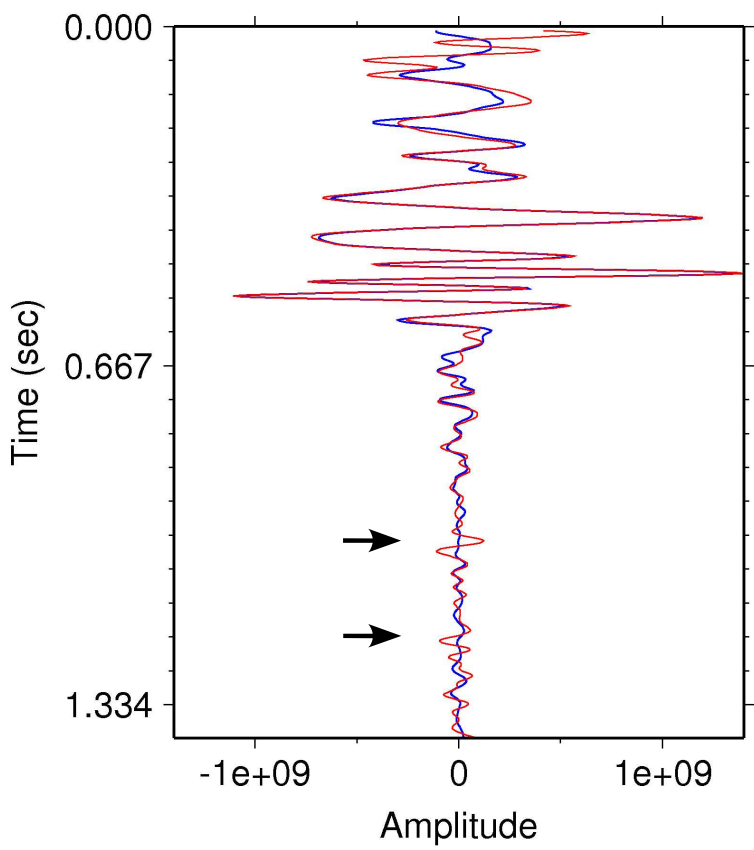

Fig. 3. Synthetic seismograms computed for the sound-speed and density profiles shown in Fig. 2. The blue line assumes that there is no suspended sediment whereas the red line includes the effects of the of suspended sediment. The intrusion at $750 \mathrm{~m}$ and the sediment load below $900 \mathrm{~m}$ produce additional reflectivity, arrowed. The seismic source function used in both cases was a zero-phase Ricker wavelet with a peak response at $20 \mathrm{~Hz}$ that has a similar vertical resolution to that used for the seismic survey shown in Fig. 1a.

shorter than its the wavelength of the seismic signal. So the reflectivity potential is best appreciated when gradients for both sound-speed and density are computed (Fig. 2f, g) which, when converted to a synthetic seismogram (Fig. 3b) shows a reflection at $\sim 1 \mathrm{~s}$ caused by the addition of the suspended sediments in the thin layer centred at $750 \mathrm{~m}$ and enhanced reflectivity from $1.17 \mathrm{~s}$. The polarity and amplitude of the modelled reflections are similar to that observed so we conclude that seismic reflection imaging is capable of imaging turbidity layers.

\section{Inversion of observed data}

To compute the quantity of suspended sediment from the observed seismic data we require an estimate of the reflection coefficient. To do this we need to calibrate the seismic reflection system using the amplitude of the seabed reflection and the first multiple (the second reflection of the seabed is caused by seismic energy trapped in the water layer) to solve for the two unknowns; the reflection coefficient and the system calibration factor (Warner, 1990). In deep water, after compensation for the spherical spreading of the wave-front 
from a point source, the amplitude of the primary reflection from sea bed is given by

$A_{\mathrm{P}}=c R$

where $R$ is the unknown reflection coefficient and $c$ is the required calibration factor. The amplitude $A_{\mathrm{M}}$ of the corresponding first sea bed multiple is

$A_{\mathrm{M}}=-c R^{2}$.

By taking the ratio of the primary to multiple amplitude, the reflection coefficient of the sea bed $R$ can be determined.

To make the calculation robust, we used the ratio of mean values and standard deviations from distributions of the seabed primary and multiple from 900 traces from a section of the profile where we observe the turbidity layer. The selected data were processed to suppress low frequency noise, corrected for spherical divergence and normal move-out then stacked with a maximum aperture of $1000 \mathrm{~m}$. This limits the maximum incident angle for reflections from the base of the channel to less than $24^{\circ}$, which is sufficient to increase the amplitude of the reflection from the turbidity layer above the ambient noise while minimises the effect of any amplitude or phase distortion of the reflections caused by the angle of incidence of the seismic energy or processing. The histograms for the seabed reflection and multiple are shown in Fig. 4a, b. The computed ratio of $A_{\mathrm{M}} / A_{\mathrm{P}}$ gives a value for the reflection coefficient at the sea-bed of $R=0.20 \pm 0.05$ which is a reasonable value for an interface between sea-water and unconsolidated sediment (Warner, 1990). Substituting back into (2) or (3) we can compute the calibration factor, $c$, of $18 \pm 3$. We can now invert amplitudes on the seismic data to reflection coefficients provided we only use data with the same processing applied as used for the calibration and, as is the case for sea-water at these frequencies, we ignore any additional transmission losses.

The top of the reflectivity interpreted as the turbidity layer is sampled at 900 locations and the mean and standard deviation are used to estimate the reflection coefficient (Eq. 2, Fig. 4c) to give a value of $R=0.00004 \pm 0.00002$. We can invert this value to estimate the sediment loading. Provided the impedance contrast is small the reflection coefficient $R$ can be approximated to $\delta Z / 2 Z$ where the impedance $Z=\rho \nu ; \rho$ is the density and $v$ is the sound-speed (Ruddick et al., 2009). Using Eq. (1), $\delta Z$ is equal to

$\delta Z=\left((1-\phi) v_{\mathrm{w}}+\phi v_{\mathrm{s}}\right)\left((1-\phi) \rho_{\mathrm{w}}+\phi \rho_{\mathrm{s}}\right)-v_{\mathrm{w}} \rho_{\mathrm{W}}$

which can be expanded to give

$\delta Z=\phi v_{\mathrm{w}} \rho_{\mathrm{s}}+\phi v_{\mathrm{s}} \rho_{\mathrm{w}}-2 \phi v_{\mathrm{w}} \rho_{\mathrm{w}}+O\left(\phi^{2}\right)$.

Ignoring the higher order terms and substituting in the values of sound-speed and density for water $\left(1470 \mathrm{~m} \mathrm{~s}^{-1}\right.$ and $1033 \mathrm{~kg} \mathrm{~m}^{-3}$ respectively) and quartz, we arrive at the relationship for the volume fraction of sediment. This is finally converted back into sediment loading to give a value of $45 \pm 25 \mathrm{mg} \mathrm{l}^{-1}$.
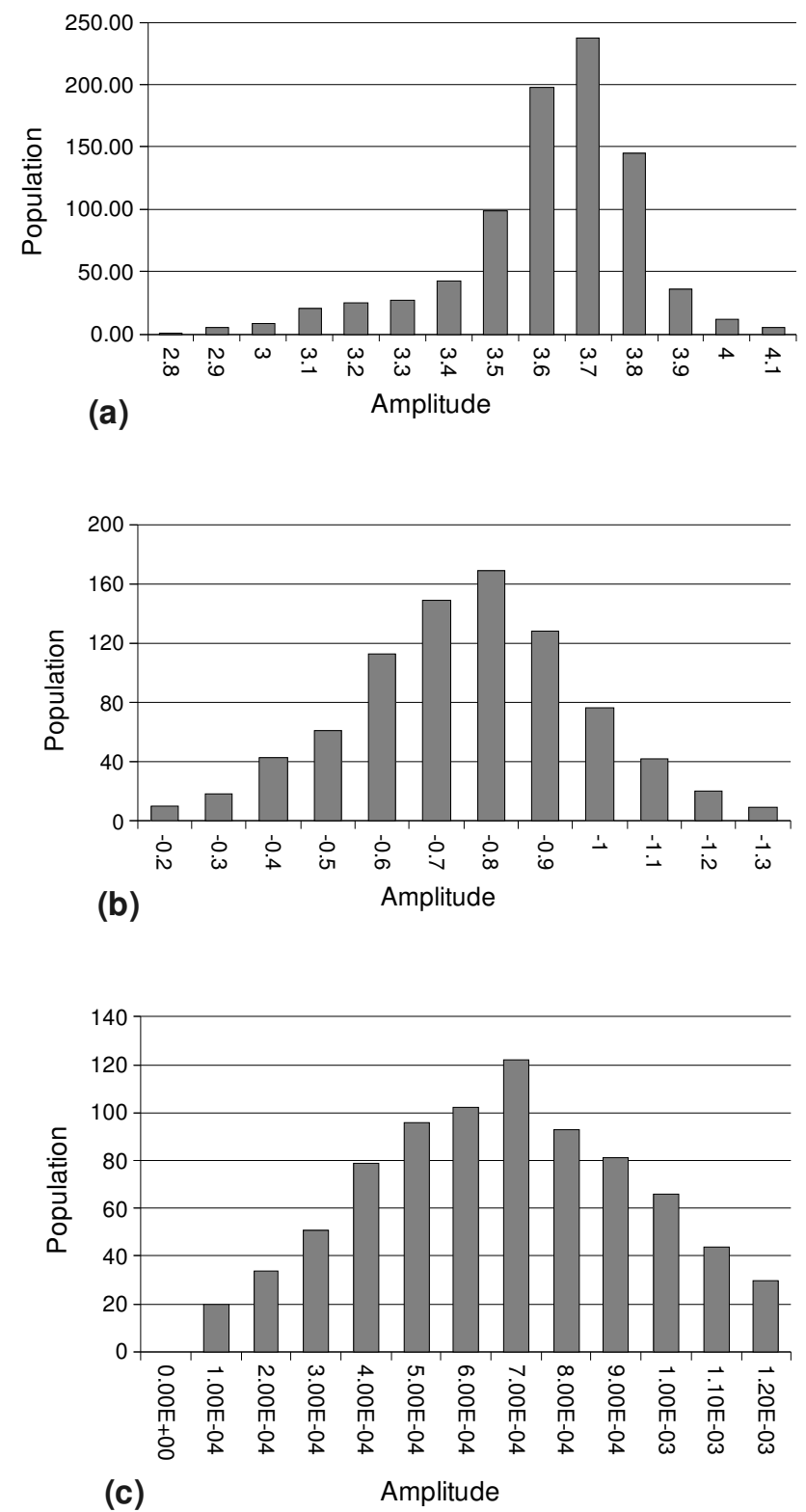

Fig. 4. Histograms of the peak amplitude of reflections picked from 900 traces from the seismic section (Fig. 1). (a) the seabed; (b) the multiple of the seabed (not shown on figure); and (c) the top of the turbidity layer. The shape of the histogram is indicative of the consistency of the reflection coefficient, the rugosity of the reflection surface in 3-D and the signal-to-noise ratio.

\section{Discussions and conclusions}

Benns and Pilgrim (1994) discussed the response of optical backscatter devices to variations in suspended particulate matter (SPM) and conclude that the particle size is the most influential physical characteristic of SPM on the instrument response; Bunt et al. (1999) also mention that deviations from sphericity in particle shape and the existence 
of radial projections can both increase scattering by $20 \%$. Using the calibration for medium size particles from Benns and Pilgrim (1994) who suggest that the sediment load for the observed SPM data could be $75-100 \mathrm{mg} \mathrm{l}^{-1}$ which is of the same order as estimated from the seismic data. As the seismic wavelength is much larger than the size of the particulate matter, this method is not sensitive to the geometry of the particles and the suspended sediment/water mixture can be considered as an equivalent homogeneous media with properties determined by Eq. (1). Compared to dry weight of total particulate matter estimated from PROCS experiment, which is given as not exceeding $10 \mathrm{mgl}^{-1}$ (van Raaphorst et al., 2001), our value for the sediment load is rather high. However they mention that the design of the filters used in the experiment was changed to avoid overloading and to match the filter parameters for particulate organic matter. Hence the results from the PROC experiment are not diagnostic for the analysis of turbidity layer. Furthermore, our estimation is in a good agreement with sediment load found in other areas of the Ocean: Ashley and Smith (2000) give values of $8-15 \mathrm{mg} \mathrm{l}^{-1}$ of suspended solids in ephemeral turbid horizons, and $25-36 \mathrm{mg} \mathrm{l}^{-1}$ for "quasipermanent" turbidity layer; and Larcombe and Carter (2004) provide values of $10-100 \mathrm{mg}^{-1}$.

A potential error is the assumption that the suspended matter is wholly composed of quartz. Stoker et al. (1998) estimates that in the FSC 8-16\% of the seabed is composed of of muddy sand facies. Assuming a similar fraction is present in the suspend matter with a lower density of $\rho=2350 \mathrm{~kg} \mathrm{~m}^{-3}$ (Sumner et al., 2009) gives us an error of $2 \%$ in our result which is well below level of error we estimated for reflection coefficient. Error due to the motion of the sediment particles is also negligible for the seismic survey. Furthermore, the region within which we observed the seismic reflection is especially homogeneous in terms of water density and thus speed of sound (Hosegood et al., 2005), with values for the BruntVäisälä frequency, $N,<10^{-3.5} \mathrm{~s}^{-1}$. Specifically, the water at this depth is vertically homogeneous FSCBW as confirmed by the data available from CTD profiles. The accuracy of the SPM concentration computed from seismic data is limited by the signal-to-noise ratio of the data and the effects on reflection amplitude caused by the local 3-D rugosity of the top of the current (Drummond et al., 2004; Hobbs et al., 2006). Further, we have assumed the upper boundary of the turbidity flow is sharp. If the boundary is gradational with a thickness of more than $10 \mathrm{~m}$ the amplitude of the reflection is reduced hence our method will tend to produce an underestimate.

From this investigation we conclude that an impedance contrast in the water column caused by turbidity layers is strong enough to be seen in seismic sections and this provides a new way to visualise this type of current to assess its dimensions and lateral structure. Further, it is possible to derive reasonable estimates of SPM in turbidity layers which are consistent with other observation methods and, because of the longer seismic wavelength, maybe more robust.
Acknowledgements. Acknowledgements to the NOIZ PROCS programme (1999-2004) for the physical oceanographic data and the FAST consortium for the seismic data. The seismic data were processed using ProMAX software provided to Durham University by Halliburton under their University Scholarship Program. Final plots were made using Octave, Seismic Unix (Cohen and Stockwell, 2010) and Generic Mapping Tools (GMT).

Edited by: O. Zielinski

\section{References}

Ashley, G. M. and Smith, N. D.: Marine sedimentation at a calving glacier margin, Bull. Geol. Soc. Am., 112, 657-667, 2000.

Benns, E. J. and Pilgrim, D. A.: The effect of particle characteristics on beam attenuation coefficient and output from an optical backscatter sensor, Neth. J. Aquat. Ecol., 28, 245-248, 1994.

Bonnin, J., van Raaphorst, W., Brummer, G.-J., van Haren, H., and Malschaert, H.: Intense mid-slope resuspension of particulate matter in the Faeroe-Shetland Channel: Short-term deployment of near-bottom sediment traps, Deep-Sea Res., Part I, 49, 14851505, 2002.

Bonnin, J., Koning, E., Epping, H. G., Brummer, G. J. A., and Grutters, M.: Geochemical characterization of resuspended sediment on the SE slope of the Faeroe-Shetland Channel, Mar. Geol., 214, 215-233, 2005.

Bonnin, J., van Haren, H., Hosegood, P. J., and Brummer, G.-J.: Burst resuspension of seabed material at the foot of the continental slope of the Rockall Channel, Mar. Geol., 226, 167-184, 2006.

Bulat, J. and Long, D.: Images of the seabed in Faroe-Shetland Channel from commercial 3D seismic data, Mar. Geophys. Res., 22, 345-367, 2001.

Bunt, J. A. C., Larcombe, P., and Jago, C.: Quantifying the response of optical back scatter devices and transmittometers to variations in suspended particulate matter, Cont. Shelf Res., 19, 1199-1220, 1999.

Cohen, J. K. and Stockwell Jr., J. W.: CWP/SU: Seismic Unix Release 42: a free package for seismic research and processing, Center for Wave Phenomena, Colorado School of Mines, 2010.

Drummond, B. J., Hobbs, R. W., and Goleby, B. R.: The effects of out-of-plane seismic energy on reflections in crustal-scale $2 \mathrm{D}$ seismic sections, Tectonophysics, 388, 213-224, 2004.

England, R. W., McBridge, J. H., and Hobbs, R. W.: The role of Mesozoic rifting in the opening of the NE Atlantic: evidence from deep seismic profiling across the Faroe-Shetland Trough, J. Geol. Soc., 162, 661-673, 2005.

Fofonoff, P. and Millard Jr., R. C.: Algorithms for computation of fundamental properties of seawater, Unesco Technical Papers in Marine Science, 44, Unesco, 1983.

Hansen, B. and Østerhus, S.: North Atlantic - Nordic Seas exchanges, Prog. Oceanogr., 45, 109-208, 2000.

Hay, A. E.: Turbidity currents and submarine channel formation in Rupert inlet, J. Geophys. Res., 92, 2883-2900, 1987.

Hobbs, R. W, Drummond, B. J., and Goleby, B. R.: The effects of three-dimensional structure on two-dimensional images of crustal seismic sections and on the interpretation of shear zone morphology, Geophys. J. Int., 164, 490-500, 2006. 
Holbrook, W. S., Páramo, P., Pearse, S., and Schmitt, R. W.: Thermohaline fine structure in an oceanographic front from seismic reflection profiling, Science, 301, 821-824, 2003.

Hosegood, P. and van Haren, H.: Near-bed solibores over the continental slope in the Faroe-Shetland Channel, Deep-Sea Res., 51, 2943-2971, 2004.

Hosegood, P., van Haren, H., and Veth, C.: Mixing within the interior of the Faeroe-Shetland Channel, J. Mar. Res., 63, 529-561, 2005.

Koenitz, D., White, N., McCave, I. N., and Hobbs, R.: Internal structure of a contourite drift generated by the Antarctic Circumpolar Current, Geochem. Geophy. Geosy., 9, Q06012, doi:10.1029/2007GC001799, 2008.

Kuijpers, A., Hansen, B., Huhnerbach, V., Larsen, B., Nielsen, T., and Werner, F.: Norwegian Sea overflow through the FaroeShetland gateway as documented by its bedforms, Mar. Geol., 188, 147-164, 2002.

Larcombe, P. and Carter, R. M.: Cyclone pumping, sediment partitioning and the development of the Great Barrier Reef shelf system: a review, Quaternary Sci. Rev., 23, 107-135, 2004.

Lewis, S. E., Sherman, B. S., Bainbridge, Z. T., Brodie, J. E., and Cooper, M.: Modelling and monitoring the sediment trapping efficiency and sediment dynamics of the Burdekin Falls Dam, Queensland, Australia, 18th, World IMACS/MODSIM Congress, Cairns, Australia, 13-17 July, 2009.

Masson, D. G., Plets, R. M. K., Huvenne, V. A. I., Wynn, R. B., and Bett, B. J.: Sedimentology and depositional history of Holocene sandy contourites on the lower slope of the Faroe-Shetland Channel, northwest of the UK, Mar. Geol., 268, 85-96, 2010

Meiburg, E. and Kneller, B.: Turbidity currents and their deposits, Annu. Rev. Fluid Mech., 42, 135-156, 2010.

Middleton, G. V.: Experiments on density and turbidity currents, Can. J. Earth Sci., 3, 523-546, 1966.

Rogers, A. L. and Ravens, T. M.: Measurement of Longshore Sediment Transport Rates in the Surf Zone on Galveston Island, Texas, J. Coastal Res., 2, 62-73, doi:10.2112/05-0564.1, 2008.
Ruddick, B., Song, H., Dong, C., and Pinheiro, L.: Water column seismic images as smoothed maps of temperature gradient, Oceanography, 22, 192-205, 2009.

Sherwin, T. J., Williams, M. O., Turrell, W. R., Hughes, S. L., and Miller, P. I.: A description and analysis of mesoscale variability in the Färoe-Shetland Channel, J. Geophys. Res., 111, C03003, doi:10.1029/2005JC002867, 2006.

Sherwin, T. J., Hughes, S. L., Turrell, W. R., Hansen, B., and Østerhus, S.: Wind driven variations in transport and the flow field in the Faroe-Shetland Channel, Polar Res., 27, 7-22, 2008.

Stoker, M. S., Hitchen, K., and Graham, C. C.: The geology of the Hebrides and West Shetland shelves, and adjacent deep water areas, United Kingdom Offshore Regional Report, British Geological Survey, London, 1993.

Stoker, M. S., Ackhurst, M. C. Howe, J. A., and Stow, D. A. V.: Sediment drifts and contourites on the continental margin off northwest Britain, Sediment. Geol., 15, 33-51, 1998.

Sumner, E. J., Talling, P. J., and Amy, L. A.: Deposits of flows transitional between turbidity current and debris flow, Geology, 37, 991-994, 2009.

Turrell, W. R., Slesser, G., Adams, R. D., Payne, R., and Gillibrand, P. A.: Decadal variability in the composition of Faroe Shetland Channel bottom water, Deep Sea Res., Part I, 46, 1-25, 1999.

van Raaphorst, W., Malschaert, H., van Haren, H., Boer, W., and Brummer, G.-J.: Cross-slope zonation of erosion and deposition in the Faeroe-Shetland Channel, North Atlantic Ocean, Deep-Sea Res., Part I, 48, 567-591, 2001.

Warner, M.: Absolute reflection coefficients from deep seismic reflections, Tectonophysics, 173, 15-23, 1990.

Wu, R.-S. and Aki, K.: Introduction: Seismic wave scattering in three-dimensionally heterogeneous earth, Pure Appl. Geophys. PAGEOPH, 128, 1-6, 1988. 